\title{
Coronary Risk Factors in Patients with Coronary Artery Ectasia : A Case-Control Study from Iran
}

\author{
Javad Ramezani ${ }^{1}$, Toktam Moghiman ${ }^{2}$, Farahzad Jabbari Azad ${ }^{3 *}$, \\ Ghazal Ghasemi ${ }^{4}$, Mahnaz Ahmadi ${ }^{5}$ and Mahmood M. Shabestari ${ }^{6}$
}

${ }^{1}$ MD. Fellowship of Interventional Cardiology, Atherosclerosis Prevention Research Center, School of Medicine, Mashhad University of Medical Sciences, Mashhad, Iran.

${ }^{2}$ Atherosclerosis Prevention Research Center, Faculty of Medicine,

Mashhad University of Medical Sciences, Mashhad, Iran.

${ }^{3}$ Allergy and Clinical Immunology, Allergy Research Center, School of Medicine,

Mashhad University of Medical Sciences, Mashhad, Iran.

${ }^{4}$ Resident of Gynecology, Mashhad University of Medical Sciences, Mashhad, Iran.

${ }^{5}$ Cardiology, Atherosclerosis Prevention Research Center, School of Medicine,

Mashhad University of Medical Sciences, Mashhad, Iran.

${ }^{6}$ Interventional Cardiology, Atherosclerosis Prevention Research Center,

School of Medicine, Mashhad University of Medical Sciences, Mashhad, Iran.

http://dx.doi.org/10.13005/bbra/2047

(Received: 06 February 2016; accepted: 13 March 2016)

\begin{abstract}
Coronary artery ectasia is a rare finding in angiography. We investigated the prevalence of coronary artery ectasia and assessed cardiovascular risk factors as probable influencing factors in this disease in our region. This study was conducted from October 2007 to March 2010 on 2500 patients visiting Imam Reza and Qaem and Razavi hospitals, Mashhad, Iran who had chest pain and were selected for angiographic studies. The study was based on reviewing angiographic films besides filling in questionnaires. 103 coronary artery ectasia cases showing $4 \%$ prevalence for this kind of coronary involvement were selected as the study group and compared with 62 patients with atherosclerosis and no ectasia as the control group. Mean age of the study and control group was 57.6 and $54.1 y r s$, respectively indicating a statistically significant difference $(p=0.032)$. The study and control groups showed no significant difference based on sex, smoking history and mean Body Mass Index (BMI). However, a BMI above 25 had a significantly higher prevalence in the study group $(p=0.036)$. Mean hs-CRP and homocystein levels were 3.4 and 11.8 in the study group and 2.3 and 8.3 in the control group, respectively, both revealing a significant difference $(p=0.002, p<0.001)$. Hyperlipidemia in ectasia patients in comparison to controls was significantly more prevalent $(p=0.001)$. The prevalence of coronary artery ectasia was $4 \%$ and cardiovascular risk factors in ectasia cases included: hyperlipidemia, high hs-CRP, and homocystein.
\end{abstract}

Key words: Ectasia, Angiography, Coronary Artery Disease, Risk factors .

Coronary artery ectasia (CAE) is a serious cardiac involvement, defined as localized coronary dilatation which exceeds the diameter of normal adjacent segments or the diameter of the

\footnotetext{
* To whom all correspondence should be addressed. Tel: +985 118 54450;

E-mail: Jabbarif@mums.ac.ir
}

patient's largest coronary vessel by 1.5 times. CAE varies in incidence from 1.5 to $5 \%$ in most literature; however, it has been reported to be as high as $10 \%$ in some nations. The exact etiology of coronary ectasia remains not well understood; however, a number of potential explanations for coronary dilatation have been proposed, including atherosclerosis, Kawasaki disease, Takayasu arteritis, congenital coronary artery disease, rare 
etiologies like syphilis, trauma or dissection and also iatrogenic causes ${ }^{1}$. Atherosclerosis, either the atheromatic plaque or the localized inflammation itself can lead to loosening and destruction of the blood vessels' connective tissue and result in vascular ectasia or aneurysm ${ }^{2-4}$. Familial hypercholesterolemia causes ectasia both through the atherosclerotic mechanism and also through its direct effect ${ }^{3,5}$. Regarding that high Homocysteine level is a risk factor for cardiovascular and cerebrovascular diseases, it could be considered as a risk factor for coronary artery ectasia as well ${ }^{1,6-7}$. Chronic inflammation and a high CRP level have been seen in companionship with coronary artery ectasia ${ }^{3}$. A subset of patients may have no evidence of a known risk factor for coronary disease; therefore they might be recognized as having idiopathic coronary artery ectasia ${ }^{1}$.

The prevalence of CAE, as determined by angiography, has been between $0.3 \%$ and $5.3 \%$ in earlier studies ${ }^{4}$. It seems that during the recent years the prevalence of CAE has increased; for instance the reported cases were as high as $10 \%$ from India in $2006^{8}$ and $9.9 \%$ from Turkey in $2010^{9}$. This rise in the prevalence of CAE as suggested by previous studies could be due to the high exposure to pesticides and fluorosis ${ }^{9}$.

The clinical manifestations of coronary artery ectasia include a wide spectrum of signs and symptoms. In many cases it has no specific clinical symptom and is usually accidentally diagnosed in angiography due to other indications. In cases which it becomes symptomatic, the most common symptom is acute coronary syndrome which could be the result of the ectasia itself, a thrombosis in the ectatic region or spontaneous stenosis in the involved coronary artery.

This study was designed to investigate the prevalence of coronary artery ectasia in our region. It also assessed the most common cardiovascular risk factors as probable influencing factors in this disease and in the same population.

\section{MATERIALSANDMETHOD}

\section{Subjects}

This is a case-control study performed from October 2007 through March 2010 in Imam Reza, Razavi and Qaem hospitals, Mashad, Iran.
During this study 2500 patients underwent coronary artery angiography; among them 103 cases of coronary artery ectasia were diagnosed that formed the study group. 62 patients who were willing to continue the study course but had no sign of ectasia, autoimmune or collagen-vascular disease and were not receiving any steroids, were recruited as the control group. The sampling method was simple and target-based. Subsequent to diagnosis of the type of arterial involvement in the performed coronary artery angiography, the patients were divided into two groups. The study group consisted of patients with coronary artery ectasia; the exact inclusion criteria for the control group were as follows: coronary artery involvement in the form of atherosclerosis, no history of autoimmune or collagen-vascular diseases and no corticosteroid consumption. None of the patients in the study group had a history of autoimmune or collagen-vascular diseases.

The study was thoroughly conducted in line with the Declaration of Helsinki. The ethics committee of Mashhad University of Medical Sciences approved the research protocol. The aim and methodology of the study was fully explained to the patients and an informed consent was obtained from each subject prior to study entrance.

The required study data were gathered through angiography films and specificallydesigned questionnaires. This specificallydesigned questionnaire consisted of sex, age, weight, height, and BMI of each individual patient which were measured by a single clinician. A complete history was taken from each patient including hypertension, diabetes, hyperlipidemia and smoking history. The diagnosis of hypertension, diabetes and hyperlipidemia was based on their history and type of current medication. A patient was defined as a smoker he/ she had been smoking for over 6 months; based on the World Health Organization's definition. Also patients having quitted smoking for over 6 months were considered as quitters. Since none of the studied cases had quitted smoking for at least 6 months, they were divided into two groups of smokers and non-smokers.

\section{Data analysis}

The data were analyzed with the application of the SPSS software (version 11.5) and by using statistical tests including Kolmogorov- 
Smirnov test, Chi-square test, Mann-Whitney test and t- test. Significance level stood at 0.05 .

\section{RESULTS}

The prevalence of coronary artery ectasia was estimated as $4 \%$ in this study.

The coronary risk factors and clinical features among the study and control groups are shown in table 1.

Body Mass Index was compared between the two groups according to Harrison's Principles of Internal Medicine's categorization ${ }^{10}$ which is shown in table 2. Mann-Whitney test showed a significant difference between the two groups $(\mathrm{P}=0.036)$.

Serum levels of high sensitivity Creactive protein and concentration of homocysteine were also compared among the two groups according to their categorization in Braunwald's Heart Disease for hs-CRP and the referred laboratory normal ranges for homocysteine ${ }^{11}$. The results are demonstrated in tables 3 and 4. A significant difference was seen between the two groups in hs-CRP $(\mathrm{P}=0.002$, Mann-Whitney test) and homocysteine $(\mathrm{P}=0.00$, Chi-Square test).

The odds ratio for different risk factors was as follows: 4.3 for hyperlipidemia, 1.5 for hsCRP, 1.4 for Homocysteine level, 1.03 for Body Mass Index level and 0.9 for both age and platelets count.

\section{DISCUSSION}

The prevalence of coronary artery ectasia was estimated as $4 \%$ in this study which is higher than the similar report in text books (1-3\%) ${ }^{11}$. Hashemvali and colleagues in Egypt estimated the

Table 1. Risk factors in the study and control groups

\begin{tabular}{|c|c|c|c|}
\hline Item & Study group $(n=103)$ & Control group $(n=62)$ & Sig. \\
\hline $\begin{array}{l}\text { Age (mean } \pm \text { standard } \\
\text { deviation) }\end{array}$ & $54.1 \pm 9.4$ & $57.6 \pm 11.2$ & $\mathrm{P}=0.032$ (t- test) \\
\hline Gender & $\begin{array}{l}85 \text { (82.8\%) Male } \\
18(17.5 \%) \text { Female }\end{array}$ & $\begin{array}{l}52(83.9 \%) \text { Male1 } \\
0 \text { (16.1\%) Female }\end{array}$ & $\mathrm{P}=0.823$ (Chi-Square test) \\
\hline $\begin{array}{l}\text { Body Mass Index (mean } \pm \\
\text { standard deviation) }\end{array}$ & $26.3 \pm 4$ & $25.3 \pm 3.5$ & $\mathrm{P}=0.128$ (t- test) \\
\hline Smoker & 34 (33\%) & $14(22.6 \%)$ & $\mathrm{P}=0.162$ (Chi-Square test) \\
\hline Diabetes & $10(9.7 \%)$ & $10(16.1 \%)$ & $\mathrm{P}=0.325$ (Chi-Square test) \\
\hline Hypertension & $62(60.2 \%)$ & $44(71 \%)$ & $\mathrm{P}=0.182$ (Chi-Square test) \\
\hline Hyperlipidemia & $43(41.7 \%)$ & $10(16.1 \%)$ & $\mathrm{P}=0.001$ (Chi-Square test) \\
\hline $\begin{array}{l}\text { hs-CRP (mean } \pm \text { standard } \\
\text { deviation) }\end{array}$ & $3.4 \pm 3.2$ & $2.3 \pm 2.3$ & $\mathrm{P}=0.000$ (Mann-Whitney test) \\
\hline $\begin{array}{l}\text { Homocysteine (mean } \pm \\
\text { standard deviation) }\end{array}$ & $11.8 \pm 5.8$ & $8.3 \pm 2.9$ & $\mathrm{P}=0.002$ (Mann-Whitney test) \\
\hline White Blood Cells count & $7197.1 \pm 1904.4$ & $8128.4 \pm 1982.4$ & $\mathrm{P}=0.404(\mathrm{t}-$ test $)$ \\
\hline Platelets count & $225223.3 \pm 79648.1$ & $245129.1 \pm 63670.1$ & $\mathrm{P}=0.011$ (Mann-Whitney test) \\
\hline
\end{tabular}

Table 2. Comparing Body Mass Index between the two groups

\begin{tabular}{lcc}
\hline $\begin{array}{l}\text { Body Mass } \\
\text { Index }\end{array}$ & $\begin{array}{c}\text { Study } \\
\text { group (n=103) }\end{array}$ & $\begin{array}{c}\text { Control } \\
\text { group(n=62) }\end{array}$ \\
\hline$<20$ & $6(5.8 \%)$ & $2(3.2 \%)$ \\
$20-25$ & $31(30.1 \%)$ & $32(51.6 \%)$ \\
$25-30$ & $49(47.6 \%)$ & $22(35.5 \%)$ \\
$30-40$ & $17(16.5 \%)$ & $6(9.7 \%)$ \\
\hline
\end{tabular}

Table 3. Comparing the Serum level of high sensitivity CRP between the two groups

\begin{tabular}{lcc}
\hline Serum hs-CRP & $\begin{array}{c}\text { Study } \\
\text { group (n=103) }\end{array}$ & $\begin{array}{c}\text { Control } \\
\text { group(n=62) }\end{array}$ \\
\hline$<1 \mathrm{mg} / \mathrm{l}$ (low risk) & $10(9.7 \%)$ & $14(22.6 \%)$ \\
$1-3 \mathrm{mg} /$ (medium risk) & $44(42.7 \%)$ & $32(51.6 \%)$ \\
$>3 \mathrm{mg} / \mathrm{l}$ (high risk) & $49(47.6 \%)$ & $16(25.8 \%)$ \\
\hline
\end{tabular}


Table 4. Comparing the concentration of Homocysteine between the two groups

\begin{tabular}{lcc}
\hline Homocysteine & $\begin{array}{c}\text { Study } \\
\text { group }(\mathrm{n}=103)\end{array}$ & $\begin{array}{c}\text { Control } \\
\text { group }(\mathrm{n}=62)\end{array}$ \\
\hline $\begin{array}{l}\text { Normal Homocysteine } 85(82.5 \%) \\
\text { Abnormal Homocysteine18 }(17.5 \%)\end{array}$ & $\begin{array}{c}62(100 \%) \\
0(0.00 \%)\end{array}$ \\
\hline
\end{tabular}

prevalence of coronary artery ectasia as $16.4 \%{ }^{12}$, whereas in three clinical trials conducted by the cardiology research center of Singapour's National University ${ }^{2}$, Japan ${ }^{5}$ and Aristotle University of Greece ${ }^{8}$ the same value was estimated as $1.2 \%$, $2.3 \%$ and $2.7 \%$, respectively. The wide difference between our study and the prior reports could be due to the following issues: a different social, economical and cultural basis in our studied population, difference in the basic health level and the genetic background or a different general prevalence due to any etiology; these could only be proven by further and more precise researches.

A significant difference was observed between the two groups based on age $(\mathrm{p}=0.032)$; The mean age of the ectasia cases was less than the control group. This was similar to the study performed in China by Li et al ${ }^{13}$ but differed from the one conducted by Waly et al in Egypt where the mean age of the ectasia cases was higher than the controls ${ }^{12}$.

Regarding that the study and control groups were matched for sex, no significant difference was observed on this basis $(\mathrm{p}=0.823)$. To note, $82.8 \%$ and $83.9 \%$ of the cases and controls were males, respectively. Although similar to findings from other reports, this could be due to the close relationship between coronary artery ectasia with atherosclerosis and underlying cardiovascular disorders which have a higher prevalence in males; it consequently results in more angiographic interventions in this gender.

When comparing the Total Body Mass index (BMI) in the study and control group by applying t-

test, no meaningful difference was detected $(\mathrm{p}=0.182)$, whereas after categorizing the cases based on Harrison's BMI grouping system, Mann-Whitney test showed a significant difference. It was seen that almost all the patients with coronary artery ectasia had a BMI over 25 while most of the controls had a normal BMI (2025). The same results were achieved in Waly et al study ${ }^{12}$.

Considering that smoking is a confirmed risk factor in cardiovascular diseases; it was also investigated in this research, where no significant difference was observed between the study and control groups (33\% vs. 22.6\%). Although this finding was in agreement with those from similar studies, but it could be said that as smoking is a major risk factor in cardiovascular diseases, therefore a remarkable divergence between patients with coronary artery ectasia and the controls with different degrees of atherosclerosis is not expected.

Since hypertension is a well-known risk factor for cardiovascular diseases, it was also taken into account in the current study. 58\%, 54.7\% and $31 \%$ of the patients in Lam, Mabuchi and $\mathrm{Li}^{2,5,13}$ studies had confirmed hypertension, respectively. None of the mentioned studies revealed any significant difference between the study and control groups. In the current study, $60.2 \%$ of the ectasia cases had hypertension but with no significant difference between the two groups $(p=0.182)$. Hence, it seems that hypertension is not a specific risk factor for coronary artery ectasia, still a well-known risk factor for all cardiovascular diseases.

In the recent studies having been conducted worldwide, diabetes has been introduced as a protective factor against the development and progression of ectasia ${ }^{14-15}$. We expected a small number of diabetic cases among the ectasia patients, which it was also supported statistically with only $9.7 \%$ of the ectasia cases having diabetes concomitantly.

In the study performed in Singapore's National University $63 \%$ of the ectasia cases had hyperlipidemia ${ }^{2}$ while in the study conducted in China by Li et al ${ }^{13}$, it was diagnosed in $16 \%$ of the ectasia cases. In the current study, hyperlipidemia had a 2.5 times higher prevalence in cases with coronary artery ectasia in comparison to controls (41.7\% vs $16.1 \%)$. This finding was statistically significant based on the Chi-square test $(\mathrm{P}=0.001)$.

Regarding the findings from previous studies mentioning the role of inflammation in coronary artery ectasia, inflammatory factors such as hs-CRP were investigated in both the study 
and control group which confirmed the expected significant difference between cases and controls in their level of hs-CRP $(\mathrm{P}=0<001)$. This finding was similar to those reported by $\mathrm{Li}$ et al ${ }^{13}$ and Yilmaz et $\mathrm{al}^{7}$ from China and Turkey, respectively. In a research conducted in 2005 by Satran et al, the level of Homocysteine in the coronary artery ectasia cases was higher than the controls $(14.9 \mathrm{mmol} / \mathrm{L}$ vs $8.6 \mathrm{mmol} / \mathrm{L}){ }^{16}$. In our study, the same level was higher in the ectasia cases in comparison to controls and the difference was statistically significant $(\mathrm{P}=0.002)$. The lowest Homocysteine level was $4.5 \mu \mathrm{mol} / \mathrm{L}$ and $5.5 \mu \mathrm{mol} / \mathrm{L}$ in males and females, respectively. The highest serum Homocysteine level was $355 \mu \mathrm{mol} / \mathrm{L}$ and $195 \mu \mathrm{mol} / \mathrm{L}$ in males and females respectively, which shows a higher Homocysteine concentration in males with coronary artery ectasia.

No significant difference was detected between the study and control group in their white blood cell count. However, the mean count was higher in the controls. In the study by Li et al a significant rise in white blood cell count was observed in coronary artery ectasia cases while no other report on this issue was found in the literature ${ }^{13}$.

\section{CONCLUSION}

The findings of this study show that hyperlipidemia, hs-CRP, and Homocysteine levels were 4.3, 1.5, 1.4 times higher in coronary ectasia cases in comparison to controls, respectively. Therefore, hyperlipidemia, high hs-CRP, and Homocysteine levels are introduced as cardiovascular risk factors in patients with ectasia in our region. Mean age and platelet count ratio in the study versus the control group was 0.9 . This fact suggests that patients with a lower age and platelet count have a higher tendency for developing coronary artery ectasia.

Further studies are required in order to better clarify the role of various risk factors and the changes in different laboratory tests in patients with coronary artery ectasia and therefore provide a better path to understanding its etiology and subsequently the best possible predictors and methods required for its prevention.

\section{ACKNOWLEDGMENTS}

The authors gratefully acknowledge the financial support provided by the Vice-Chancellor of Mashhad University of Medical Sciences for this research. We also thank the medical, technical and nursing staff of the Interventional Cardiology departments of Imam Reza, Razavi and Qaem Hospitals.

\section{REFERENCES}

1. Boles U, Eriksson P, Zhao Y, Henein MY Coronary artery ectasia: remains a clinical dilemma. Coron Artery Dis 2010; 21(5): 31820.

2. Lam CS, Ho KT. Coronary artery ectasia: a tenyear experience in a tertiary hospital in Singapore. Ann Acad Med Singapore 2004; 33(4): 419-22.

3. Li JJ, Li Z, Li J. Is any link between inflammation and coronary artery ectasia?. Med Hypotheses 2007; 69(3): 678-83.

4. Sharma SN, Kaul U, Sharma S, Wasir HS, Manchanda SC, Bahl VK, et al. Coronary arteriographic profile in young and old Indian patients with ischaemic heart disease: a comparative study. Indian Heart J 1990; 42(5): 365-9.

5. Mabuchi H, Michishita I, Sakai Y, Sakai T, Ikawa $\mathrm{T}$, Genda A, et al. Coronary ectasia in a homozygous patient with familial hypercholesterolemia. Atherosclerosis 1986; 59(1): 43-6.

6. Turhan H, Erbay AR, Yasar AS, Bicer A, Sahin $\mathrm{O}$, Basar N, et al. Plasma homocysteine levels in patients with isolated coronary artery ectasia. Int J Cardiol 2005; 104 (2): 158-62.

7. Yilmaz H, Tayyareci G, Sayar N, Gurkan U, Tangurek B, Asilturk R, et al. Plasma soluble adhesion molecule levels in coronary artery ectasia. Cardiology 2006; 105 (3): 176-81.

8. Giannoglou GD, Antoniadis AP, Chatzizisis YS, Damvopoulou E, Parcharidis GE, Louridas GE. Prevalence of ectasia in human coronary arteries in patients in northern Greece referred for coronary angiography. Am J Cardiol 2006; 98(3): 314-8.

9. Akcay S, Turker Y, Ozaydin M, Yucel H, Altinbas A. Frequency of coronary artery ectasia among patients undergoing cardiac catheterization. Anadolu Kardiyol Derg 2010; 10 (2): 191. 
10. Fauci A, Braunwald E, Kasper DL, Hauser SL, Longo DL, Jameson JL, et al. Harrison's Principles of Internal Medicine. 17 ed. New York: McGraw-Hill Professional; 2008.

11. Marrow D, Libby P, Bonow R, Mann D, Zipes D. Braunwald Heart disease: a textbook of cardiovascular medicine. 8 ed. New York: saunders/Elsevier; 2008.

12. Waly HM, Elayda MA, Lee VV, el-Said G, Reul GJ, Hall RJ. Coronary artery ectasia in Egyptian patients with coronary artery disease. Tex Heart Inst $J$ 1997; 24(4): 349-52.

13. Li JJ, Nie SP, Qian XW, Zeng HS, Zhang CY. Chronic inflammatory status in patients with coronary artery ectasia. Cytokine 2009; 46(1): 61-4.

14. Saglam M, Karakaya O, Barutcu I, Esen AM, Turkmen M, Kargin R, et al. Identifying cardiovascular risk factors in a patient population with coronary artery ectasia. Angiology 2007; 58(6): 698-703.

15. Yao YA, Zhang SY, Wu W, Chen LF. [The clinical manifestations and angiographic characteristics of coronary artery ectasia]. Zhonghua Nei Ke Za Zhi 2010; 49 (5): 389-91.

16. Satran A, Bart BA, Henry CR, Murad MB, Talukdar S, Satran D, et al. Increased prevalence of coronary artery aneurysms among cocaine users. Circulation 2005; 111(19): 2424-9. 